\title{
Atypical Kaposi's sarcoma in young inmunocompetent patient*
}

\author{
Josefa Sánchez-López ${ }^{1}$ \\ María Librada Porriño-Bustamante ${ }^{3}$ \\ Ramón Naranjo-Sintes ${ }^{5}$
}

\author{
Santiago Pérez-Parra ${ }^{2}$ \\ José Aneiros-Fernández ${ }^{4}$ \\ María Antonia Fernández-Pugnaire ${ }^{5}$
}

DOI: http:/ / dx.doi.org/10.1590/abd1806-4841.20175564

\begin{abstract}
Kaposi's sarcoma is a rare tumor associated with human herpes virus 8 (HHV-8) infection. Four main clinical subtypes have been described. This study reports on a form of KS in an HIV negative and immunocompetent middle-aged man. The only remarkable factor is that he has sex with other men. This form of Kaposi's sarcoma is rare. It occurs more in younger patients than in the classic form, is limited to the skin, and is associated with a good prognosis. The means of transmission of the virus is through saliva in oroanal or orogenital sexual practices. Mechanisms of tumor development are still not well known. Given the possible increased number of this variant, it would be interesting to extend this study.
\end{abstract}

Keywords: Sarcoma, Kaposi; Herpesvirus 8, Human; HIV Infections; Homosexuality; Homosexuality, male

\section{INTRODUCTION}

Kaposi's sarcoma (KS) is a rare systemic and multifocal tumor in endothelial cells (vascular/ lymphatic) that is associated with human herpesvirus 8 (HHV-8) infection. Four clinical subtypes have been described. ${ }^{1,2}$ Classic or European KS, appears in the elderly from the Mediterranean area and appears as slow-growing nodules or plaques located mainly on the lower extremities. The endemic or African subtype mainly affects young adults or children and is mostly locally-invasive and/or associated with visceral disease. Iatrogenic KS is mostly observed in organ transplant recipients with immunosuppressive treatment and disappears with the withdrawal of immunosuppression. The last subtype is KS associated with HIV, which appears in young patients, predominantly homosexual or bisexual men, with multifocal skin lesions, frequently along with mucosal and/or visceral involvement and a rapid progression of the disease.

Recently, several cases of KS which do not fit these subgroups have been described. We present here a new case of a middle-aged man who has sex with men, HIV negative, and with no associated immunodeficiency.

\section{CASE REPORT}

A 52-year-old man was admitted to our clinic, complaining of a violaceous nodule of about $2 \mathrm{~cm}$ in diameter located on the left forearm (Figure 1). He also presented erythematous-violaceous nodular lesions, some of which were ulcerated, located on the right arm, the back of his right hand, and his left leg and foot (Figure 2). The patient reported the appearance of previous similar lesions that had vanished spontaneously over a period of 2 years. Neither mucosal nor visceral involvement were noted.

Histopathological evaluation of the forearm lesion revealed a strong proliferation of spindle-shaped cells with cytological atypia, outlining irregular slits and clefts, which is consistent with the diagnosis of KS (Figure 3). Immunohistochemistry for HHV-8 was positive.

There were no abnormalities in the differential blood nor in B and T cell subcounts. Lymphocytes T CD4+ were 1091/ $\mu$ l

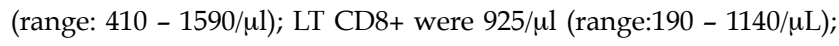
and $\mathrm{CD} 4+/ \mathrm{CD} 8+$ ratio was: 1.18 (range: $0.8-2.0$ ). HIV tests were repeatedly negative. $\mathrm{CMV}, \mathrm{EBV}, \mathrm{HCV}, \mathrm{HBV}$, and syphilis tests were negative as well. Serological tests for HHV-8 were positive.

\footnotetext{
Work submitted on 20.01.2016

Approved by the Advisory Board and accepted for publication on 20.06.2016

* Work performed at the Department of Dermatology, Hospital Universitario San Cecilio, Granada, Spain.

Financial support: None

Conflict of interest: None

Department of Dermatology, Complejo Hospitalario La Mancha Centro, Alcázar de San Juan, Ciudad Real, Spain.

Department of Microbiology, Hospital Universitario San Cecilio, Granada, Spain

Department of Dermatology, Hospital La Zarzuela, Madrid, Spain.

Department of Pathology, Hospital Universitario San Cecilio, Granada, Spain.

Department of Dermatology, Hospital Universitario San Cecilio, Granada, Spain.

C2017 by Anais Brasileiros de Dermatologia
} 


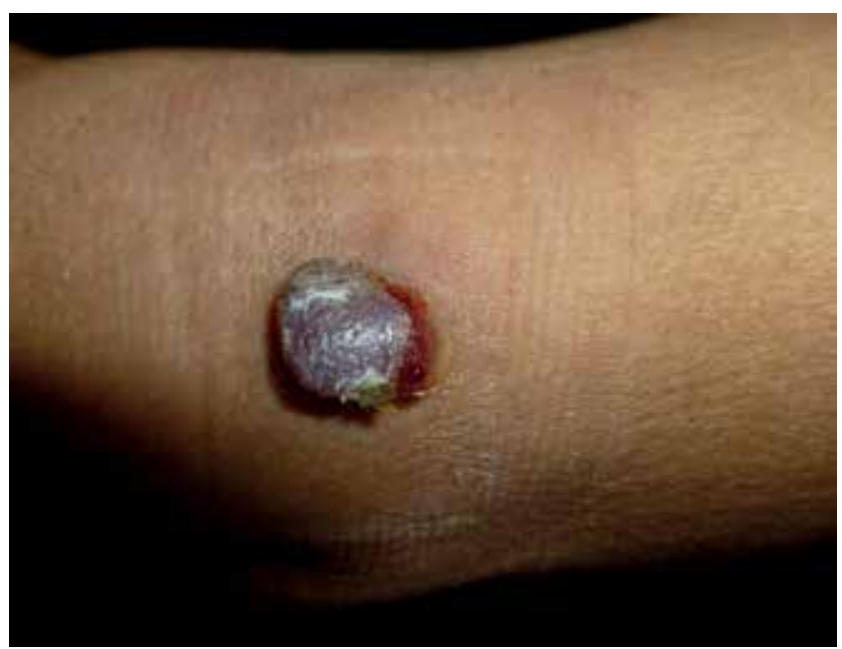

FIGURE 1: Violaceous nodule of $2 \mathrm{~cm}$ in diameter, with based ulceration, located on the left forearm

In addition, $300 \mu \mathrm{l}$ of patient saliva were extracted, the sample was inoculated into a viral transport medium and sent to the National Center for Microbiology, Institute of Health Carlos III (Madrid), for the investigation of herpes virus using rt-PCR. The multiplex PCR was positive for HHV-type 8, and negative for type 6 and 7 .

Subsequently, other similar lesions were also removed, with the histological results being consistent with an SK diagnosis. The patient is currently being followed-up periodically. Interestingly enough, the patient reported having had sex with other men about 20 years ago.

\section{DISCUSSION}

Kaposi sarcoma in HIV-negative men who have sex with men has only been reported sporadically, but most cases fulfill the same characteristics: patients around 50 years of age, with a Classic clinical presentation of Kaposi's sarcoma, limited to the skin and associated with a good prognosis. No immunodeficiencies are presented with normal humoral and cellular immunity. These patients often have oral-genital and/or oroanal sexual practices. ${ }^{3}$ The largest study of patients with this clinical form was that performed in France in 2008, which includes 28 patients. ${ }^{4}$

Our patient fulfilled the characteristics mentioned above, with the singularity of the spontaneous vanishing of some of the lesions. It is thought that the development of the disease is modulated by the patient's immune status and other factors are still quite unknown. Furthermore, controversy over whether Kaposi's sarco$\mathrm{ma}$ is a reversible proliferative disorder or a true malignancy is still present. It is thought that it begins as a polyclonal disease and ends as a monoclonal one. ${ }^{5}$ This would explain why lesions may regress spontaneously when they are in a polyclonal phase.

HHV-8 is the cause of Kaposi's sarcoma, but its seroprevalence and the means of transmission varies with the clinical form. ${ }^{6,7}$
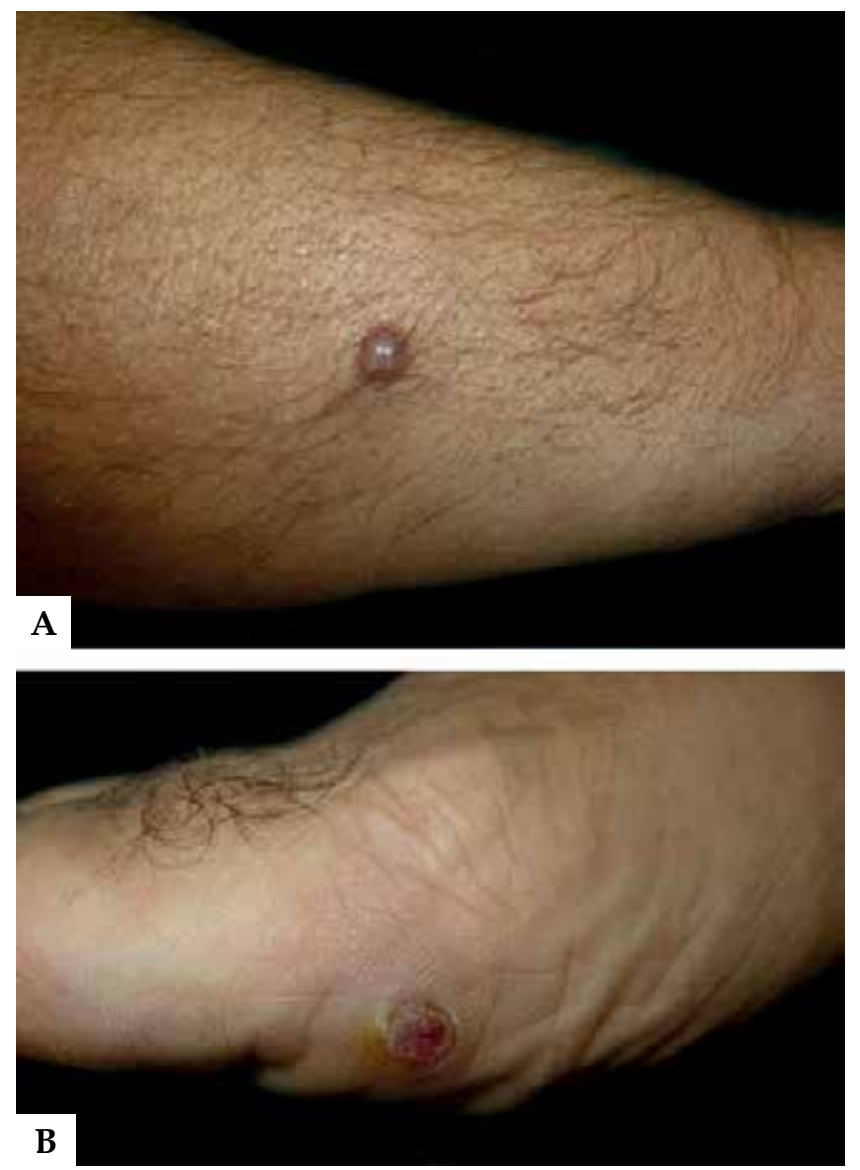

Figure 2: A - Violaceous nodule of $0.7 \times 0.8 \mathrm{~cm}$ in diameter, located on the right forearm. B - Violaceous nodule of $1 \times 1.5 \mathrm{~cm}$ in diameter with eroded surface, located on the inside portion of the left foot
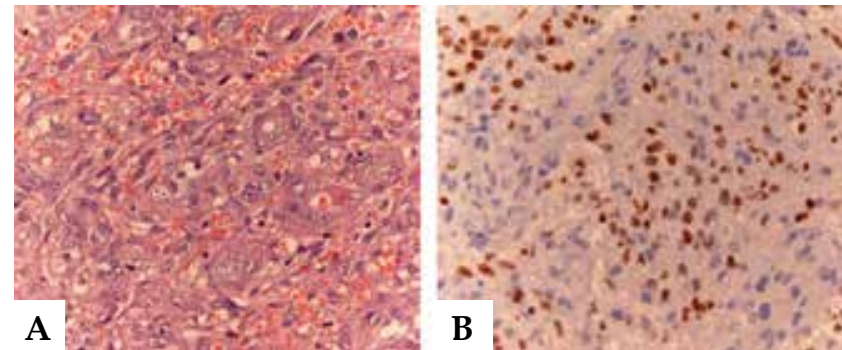

FigURE 3: A - Histo-pathological evaluation revealed proliferation of spindle-shaped cells with cytological atypia, outlining a broad network of vascular spaces similar to slits, with some mitotic figures, consistent with KS in the nodular phase. Hyaline globules, which are a characteristic but not absolutely specific finding of Kaposi's sarcoma, are also observed (Hematoxylin, original magnification, X200). B - Immunohistochemical analysis for human herpesvirus 8 (HHV-8) in Kaposi sarcoma revealed a strong immunoreactivity of HHV-8 (Hematoxylin, original magnification, X200) 
In northern Europe and the United States, HHV 8 seroprevalence is low in the general population $(<5 \%)$, but in homosexual or bisexual men, a seroprevalence of up to $25 \%$ has been described. Epidemiologic studies have shown that oral exposure to infectious saliva is the major risk factor for the acquisition of HHV-8 between homosexual or bisexual men, that the oropharynx is a site of active viral replication, and that the seroprevalence of HHV-8 in HIV-positive male patients who have sex with men is higher. ${ }^{8}$ In our patient, HHV-8 positivity in saliva is also demonstrated. Another less frequent means of transmission is via blood and blood products. ${ }^{9}$

Therefore, given the high prevalence of HHV-8 among homosexual and bisexual men and its strong association with Kaposi's sarcoma, an increased risk of Kaposi's sarcoma in immunocompetent male patients who have sex with men is noted, and we should be alert because the prevalence of this clinical form might increase in the coming decades. Therapeutic options do not differ from classic Kaposi's sarcoma. The objective is to control the symptoms, since no curative therapy is known. Isolated lesions can be treated with local excision, with cryosurgery, or by laser. Further options are imiquimod, topical alitretinoin $0.1 \%$ gel, or radiation. If systemic involvement is observed, interferon combination therapy is quite well tolerated. Liposomal doxorubicin, radiotherapy may also be applied. ${ }^{7,10}$

In conclusion, we report a new case of Kaposi's sarcoma in a homosexual patient, who is immunocompetent and presents an involution of some lesions. We believe it would be interesting to investigate the mechanisms by which Kaposi's sarcoma develops in immunocompetent patients.

\section{REFERENCES}

1. Almohideb M, Watters AK, Gerstein W. Familial classic Kaposi sarcoma in two siblings: case report and literature review. J Cutan Med Surg. 2013;17:356-61.

2. Ferreira $\mathrm{CP}$, Miranda A, Nery JA. Kaposi's sarcoma simulating verrucous syndrome. Braz J Infect Dis. 2015;19:444-5.

3. Potthoff A, Brockmeyer NH, Stücker M, Wieland U, Kreuter A, Competence Network HIV AIDS. Kaposi Sarcoma in a HIV uninfected man who has sex with men. Eur J Med Res. 2010;15:79-80.

4. Lanternier F, Lebbé C, Schartz N, Farhi D, Marcelin AG, Kérob D, et al. Kaposi's sarcoma in HIV- negative men having sex with men. AIDS. 2008;22:1163-8.

5. Judde JG, Lacoste $V$, Brière J, Kassa-Kelembho $E$, Clyti $E$, Couppié $P$, et al. Monoclonality or oligoclonality of human herpesvirus 8 terminal repeat sequences in Kaposi's sarcoma and other diseases. J Natl Cancer Inst. 2000;92:729-36.

6. Chang Y, Cesarman E, Pessin MS, Lee F, Culpepper J, Knowles DM, et al. Identification of herpesvirus-like DNA sequences in AIDS-associated Kaposi's sarcoma. Science. 1994;266:1865-9.

7. Schulz TF. Epidemiology of Kaposi's sarcoma-associated herpesvirus/human herpesvirus 8. Adv Cancer Res. 1999;76:121-60.

8. Pauk J, Huang ML, Brodie SJ, Wald A, Koelle DM, Schacker T, et al. Mucosal shedding of human herpesvirus 8 in men. N Engl J Med. 2000;343:1369-77.

9. Florek AG, Eilers D, Armstrong AW. A case of Kaposi sarcoma in an immunocompetent, heterosexual Irish man: a discussion of etiology and viral transmission. Dermatol Online J. 2015;21. pii: 13030/qt1d6409wz.

10. Trujillo JM, Alves NR, Medeiros PM, Azulay-Abulafia L, Alves Mde F, Gripp AC. Clinical exuberance of classic Kaposi's sarcoma and response to radiotherapy. An Bras Dermatol. 2015 Nov-Dec;90(6):883-6.

\author{
MAILING ADDRESS: \\ Josefa Sánchez-López \\ Av Doctor Oloriz, 16 \\ 18012, Granada, Spain. \\ E-mail: josefasanchez294@gmail.com
}

How to cite this article: Sánchez-López J, Pérez-Parra S, Porriño-Bustamante ML, Aneiros-Fernández J, Naranjo-Sintes R, Fernández-Pugnaire MA. Atypical Kaposi’s sarcoma in young inmunocompetent patient. An Bras Dermatol. 2017;92(5 Suppl 1): 24-6. 